\title{
Sodium tanshinone IIA sulfonate attenuates angiotensin II-induced collagen type I expression in cardiac fibroblasts in vitro
}

\author{
Le Yang ${ }^{1 *}$, Xiao-Jing Zou ${ }^{2 *}$, Xiang Gao ${ }^{3 *}$, \\ Hao Chen ${ }^{4}$, Jin-Long Luo ${ }^{1}$, Zhao-Hua Wang ${ }^{1}$, \\ Qian-Sheng Liang ${ }^{1}$, Guang-Tian Yang ${ }^{1,5}$ \\ ${ }^{1}$ Department of Emergency Medicine \\ ${ }^{3}$ Department of Geronotology \\ Tongji Hospital, Tongji Medical College \\ Huazhong University of Science and Technology \\ Hubei 430030, China \\ ${ }^{2}$ Department of Anesthesiology \\ Union Hospital, Tongji Medical College \\ Huazhong University of Science and Technology \\ Hubei 430022, China \\ ${ }^{4}$ School of Medicine and Health Administration \\ Tongji Medical College \\ Huazhong University of Science and Technology \\ Hubei 430030, China \\ ${ }^{5}$ Corresponding author: Tel, 86-27-83662660; \\ Fax, 86-27-83662660; E-mail, gtywh@yahoo.com.cn \\ *These authors contributed equally to this work. \\ DOI 10.3858/emm.2009.41.7.056
}

Accepted 26 February 2009

Abbreviations: Ang II, angiotensin II; CFs, cardiac fibroblasts; MMP-1, matrix metalloproteinase-1; NAC, N-acetylcysteine; ROS, reactive oxygen species; STS, sodium tanshinone IIA sulfonate

\footnotetext{
Abstract

Cardiac fibrosis occurs after pathological stimuli to the cardiovascular system. One of the most important factors that contribute to cardiac fibrosis is angiotensin II (Ang II). Accumulating studies have suggested that reactive oxygen species (ROS) plays an important role in cardiac fibrosis and sodium tanshinone IIA sulfonate (STS) possesses antioxidant action. We therefore examined whether STS depresses Ang II-induced collagen type I expression in cardiac fibroblasts. In this study, Ang II significantly enhanced collagen type I expression and collagen synthesis. Meanwhile, Ang II depressed matrix metalloproteinase-1 (MMP-1) expression and activity. These responses were attenuated by STS. Furthermore, STS depressed the intracellular generation of
}

ROS, NADPH oxidase activity and subunit $\mathrm{p} 47^{\text {phox }}$ expression. In addition, N-acetylcysteine the ROS scavenger, depressed effects of Ang II in a manner similar to STS. In conclusion, the current studies demonstrate that anti-fibrotic effects of STS are mediated by interfering with the modulation of ROS.

Keywords: angiotensin II; collagen; fibrosis; heart; reactive oxygen species; tanshinone

\section{Introduction}

Cardiac fibrosis is characterized by a disproportionate accumulation of extracellular matrix (ECM) proteins that occurs after myocyte death, inflammation, hypertrophy, and stimulation by a number of hormones, cytokines, and growth factors (Wood, 2002; Kass et al., 2004; Jaana et al., 2005). Among the ECM proteins, collagens constitute up to $85 \%$ (Brown, 2005). Collagens are proteins that consist of a triple helix of polypeptide chains and globular domains, and comprise a family of proteins of at least 19 genetically distinct types, among which type I and type III constitute two-thirds. As in the form of thick fiber with a high tensile strength, collagen type I content is considered a major determinant of myocardial stiffness. Cardiac fibroblasts (CFs) are the major source of collagen in the myocardium. Collagen type I accumulation in the heart depends not only on its production, but also on its degradation, which is performed by proteinases, such as matrix metalloproteinase-1 (MMP-1) (Heeneman et al., 2003).

Angiotensin II (Ang II) plays a critical role in cardiac fibrosis (Weber et al., 1991; Gibbons, 1998). In CFs, Ang II can upregulate collagen type I expression through stimulation oxidative stress (Cohn et al., 2000). Oxidative stress induces remodeling of the myocardium and regulates collagen metabolism in a variety of non-cardiac cells, such as lung and skin fibroblasts and human venous endothelial cells. Moreover, Ang II stimulation of the type 1 Ang II receptor has been shown to regulate collagen type I degradation by attenuating the activity and expression of collagen degrading enzyme MMP-1 in rat CFs (Chen et al., 2004a). Despite the physiopathologic significance of fibrosis, 


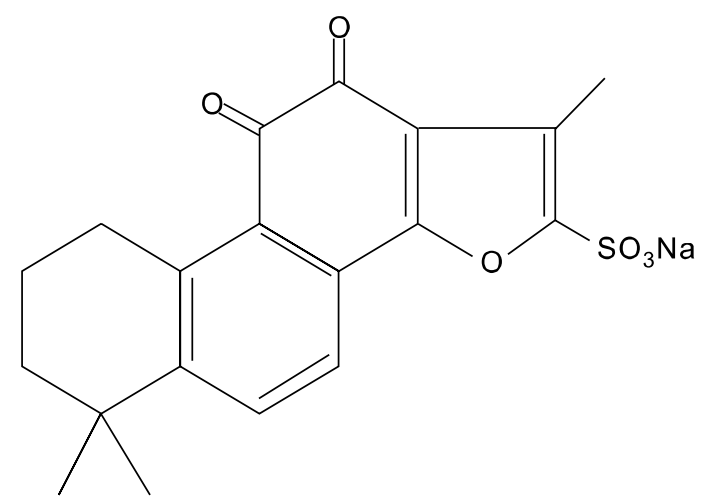

Figure 1. The molecular structure of STS.

no effective treatment strategies exist.

Sodium tanshinone IIA sulfonate (STS, Figure 1) is a derivative of tanshinone IIA which is a lipid-soluble pharmacologically active component isolated from the rhizome of the Chinese herb Salvia miltiorrhiza, a well-known traditional Chinese medicine used for the treatment of cardiovascular diseases such as coronary heart disease (Zhao et al., 1996). Recently, STS was shown to possess antioxidant action (Wang et al., 2008; Yang et al., 2008). In this paper, we explored the effects and mechanisms of STS on Ang II-induced collagen type I expression in CFs in vitro; then raised the experimental basis for using STS to cardiac fibrosis in clinic.

\section{Results}

\section{Effect of STS on Ang II-Induced ROS generation}

A previous study showed that there was minimal ROS generation in CFs in the control state (Lijnen et al., 2006). However, on treatment with Ang II, there was a marked increase in intracellular production of ROS, which played a key role in cardiac fibrosis. As STS was shown to possess some antioxidant action, we examined the effect of STS $(3,10,30 \mu \mathrm{M})$ on Ang II-increased intracellular ROS generation. STS suppressed ROS formation in CFs as measured after Ang II treatment for $12 \mathrm{~h}$, while STS alone had no effect on ROS generation (Figure 2). These data, therefore, clearly demonstrated that STS could decrease ROS production.

\section{Effects of STS on the Ang II-induced collagen type I expression and collagen synthesis}

As it is shown in Figure 3, Ang II significantly enhanced collagen type I expression, which was attenuated by the pretreatment with STS $(3,10,30 \mu \mathrm{M})$.
Consistent with the increase of collagen expression, Ang II $(0.1 \mu \mathrm{M})$ caused a significant increase in the rate of $\left[{ }^{3} \mathrm{H}\right]$ proline incorporation, which was also significantly depressed by the pretreatment with STS. To determine whether the inhibition of Ang II-induced collagen type I expression and collagen synthesis by STS is via a decrease in ROS production, we employed $\mathrm{N}$-acetyl-L-cysteine (NAC), a known antioxidant. The results showed that NAC (8 mM) significantly reduced collagen type I expression and collagen synthesis induced by Ang II, qualitatively similar to STS (Figure 3). These findings implied that STS inhibited Ang II-induced fibrotic responses via attenuation of ROS in CFs.

\section{Effects of STS on the Ang II-induced MMP-1 expression and activity}

Collagen type I accumulation in the heart depends not only on its production, but also on its degradation, which is performed by proteinases, such as matrix metalloproteinase-1 (MMP-1). Therefore, we explored the effects of STS on the Ang II-induced MMP-1 expression and MMP-1 activity. As it is shown in Figure 4, Ang II significantly depressed MMP-1 expression and activity. These effects were significantly attenuated by pretreatment with STS $(3,10,30 \mu \mathrm{M})$. To determine whether these effects of STS were via a decrease in ROS production, we employed NAC. As shown in Figure 4, the effects of Ang II on MMP-1 expression and activity were significantly suppressed by NAC in CFs. These findings implied that STS promoted collagen degradation via attenuation of ROS in CFs.

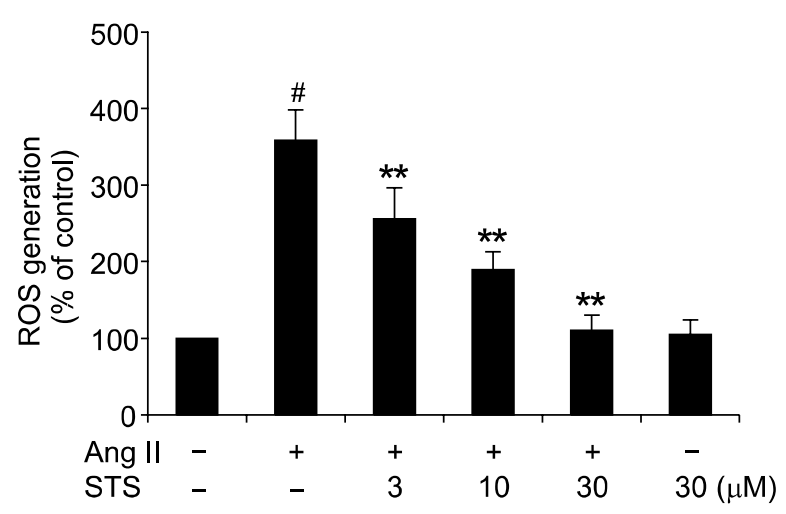

Figure 2. Effects of STS on Ang II-induced production of ROS. Cardiac fibroblasts were pretreated with STS $(3,10,30 \mu \mathrm{M})$ for 30 min before stimulation with $0.1 \mu \mathrm{M}$ Ang II. After $12 \mathrm{~h}$, DCF fluorescence was measured by fluorospectrophotometer analysis. The experiments were repeated five times with reproducible results. ${ }^{\#} P<0.01$ vs. control; ${ }^{* *} P<$ 0.01 vs. Ang II group. 

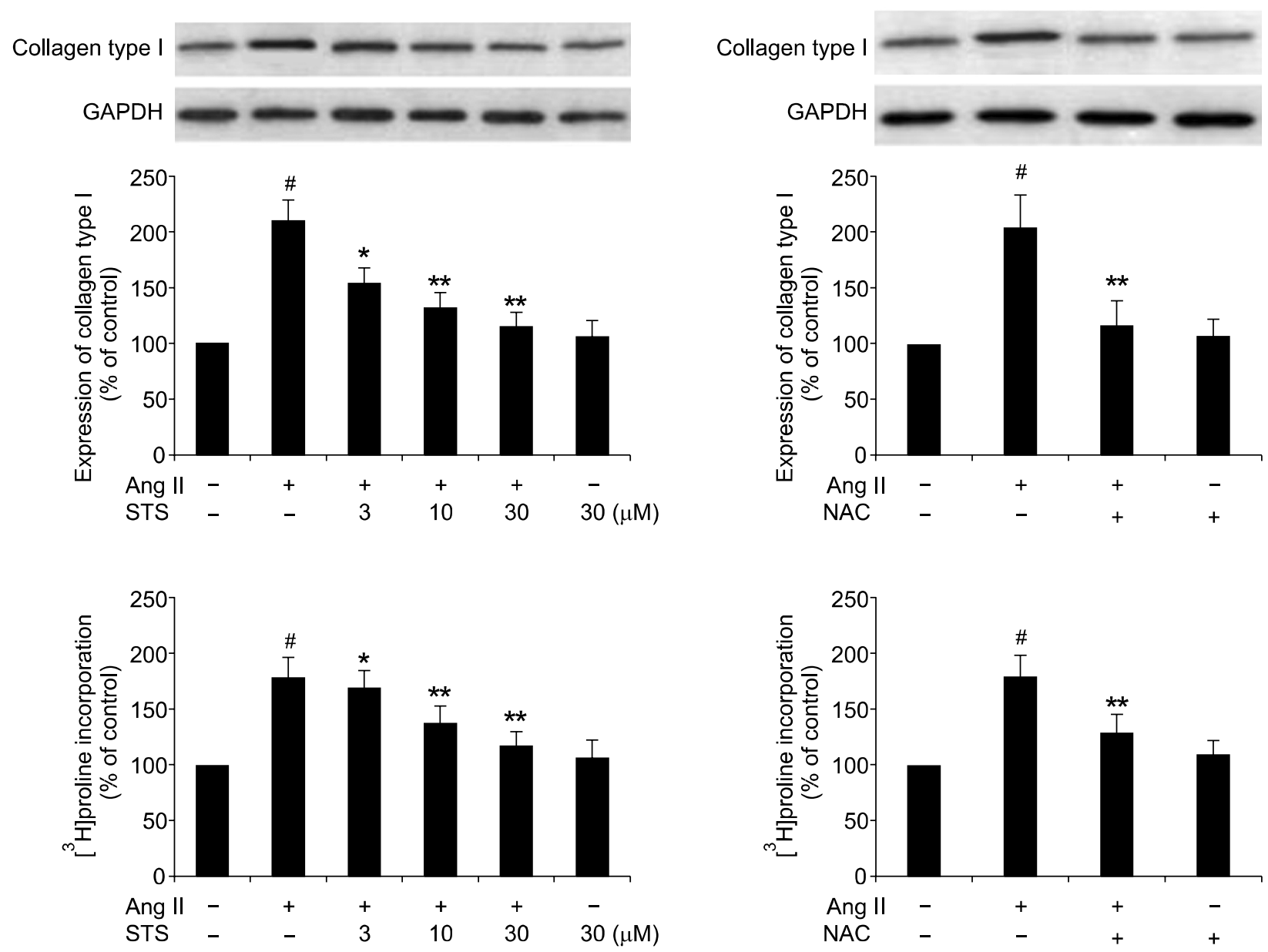

Figure 3. Effects of STS on the Ang II-induced collagen type I expression and collagen synthesis. Cardiac fibroblasts were pretreated with STS $(3,10,30$ $\mu \mathrm{M})$ for $30 \mathrm{~min}$ before stimulation with $0.1 \mu \mathrm{M}$ Ang II. After $24 \mathrm{~h}$, collagen type I expression was determined with the Western Blot and collagen synthesis was determined with the $\left[{ }^{3} \mathrm{H}\right]$ proline incorporation. The experiments were repeated five times with reproducible results. ${ }^{\sharp} P<0.01$ vs. control; ${ }^{*} P<0.05$ and ${ }^{* *} P<0.01$ vs. Ang II group.

\section{Effects of STS on Ang Il-induced fibroblast proliferation}

The effect of STS on the fibroblast proliferation was assessed by MTT assay and DNA synthesis assay ([3H]thymidine incorporation). Recent studies reported that Ang II was associated with fibroblast proliferation (Chen et al., 2004b; Chen and Mehta, 2006; Zhou et al., 2007). In the present study, we examined fibroblast proliferation in response to Ang II and its modulation by the pretreatment of STS. The data showed that, Ang II did induce CFs proliferation, whereas STS $(3,10,30 \mu \mathrm{M})$ did not induce obvious inhibitory effect on fibroblast proliferation (Figure 5).

\section{Effect of STS on Ang Il-induced NADPH oxidase activity and subunit $\mathrm{p} 47^{\text {phox }}$ expression}

To determine the mechanisms of STS-induced de- crease in ROS generation, we examined NADPH oxidase activity and subunit $\mathrm{p} 47^{\mathrm{phox}}$ expression in CFs with the treatment of Ang II and STS using cytochrome $\mathrm{c}$ reduction assay. Ang II $(0.1 \mu \mathrm{M})$ increased NADPH oxidase activity and subunit p $47^{\text {phox }}$ expression. These responses were markedly depressed by treatment of STS.

\section{Discussion}

Cardiac fibrosis, a common complication of hypertension, increases the risk for cardiac ischemia, left ventricular dysfunction and sudden cardiac death, represents a very strong predictor of cardiovascular mortality and death of all causes and is recognized as a risk factor for the development of congestive heart failure (Weber et al., 1994, 1995; Fedak et al., 2005). The regulation of the ECM of the heart is essential to understanding the chronic 

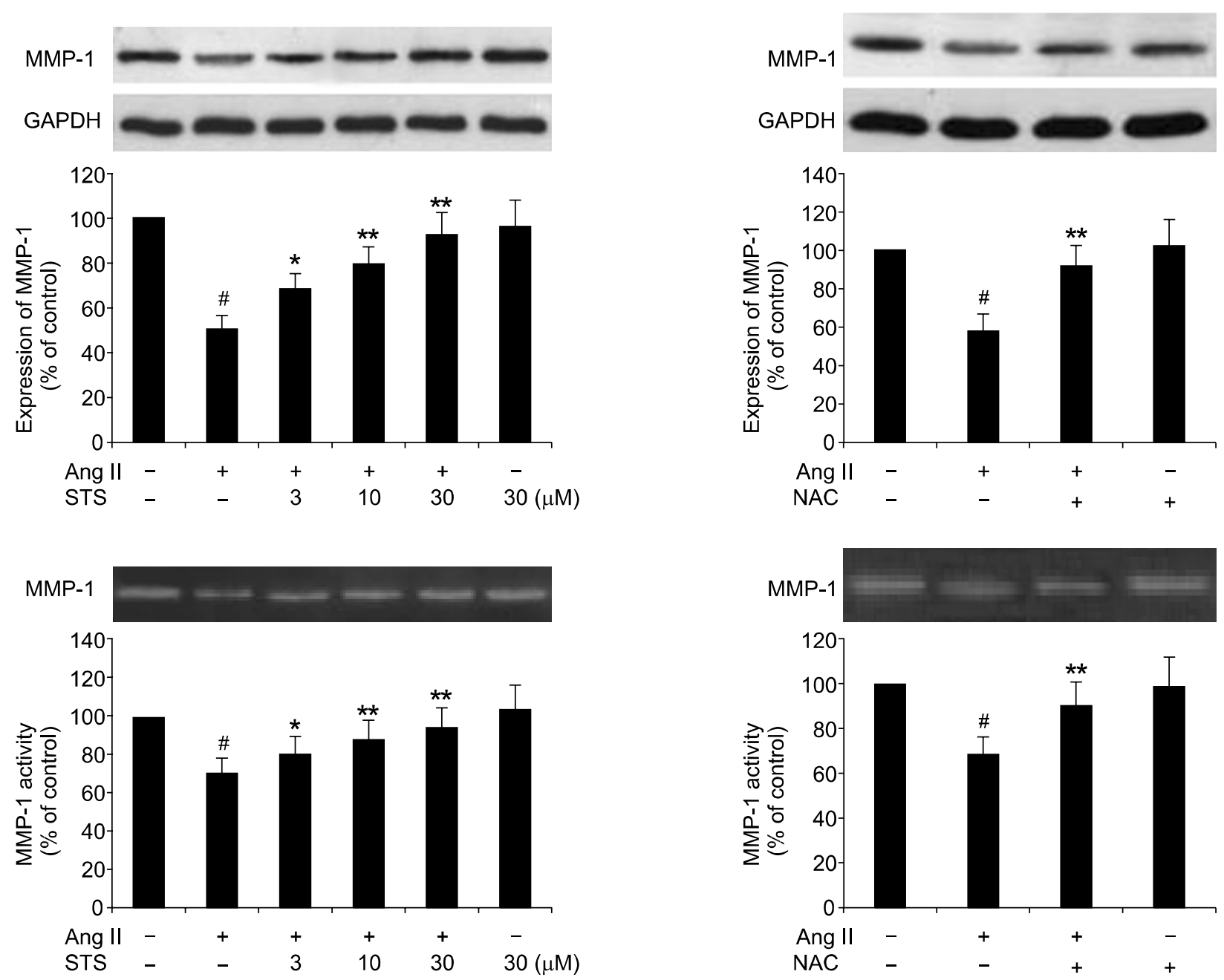

Figure 4. Effects of STS on the Ang II-induced MMP-1 expression and activity. Cardiac fibroblasts were pretreated with STS $(3,10,30 \mu \mathrm{M})$ for 30 min before stimulation with $0.1 \mu \mathrm{M}$ Ang II. After $24 \mathrm{~h}$, MMP-1 expression was determined with the Western Blot and MMP-1 activity was determined with the zymography. The experiments were repeated five times with reproducible results. ${ }^{\#}<0.01$ vs. control; ${ }^{*} P<0.05$ and ${ }^{* *} P<0.01$ vs. Ang II group.

changes in heart function in the above disease states (Brown et al., 2007). Excessive collagen is clearly detrimental to cardiac function (Kawano et al., 2000). One of the most important factors contributing to the development of cardiac fibrosis is Ang II (Sun and Weber, 2003; Kumar et al., 2008). Most of the known effects of Ang II were mediated by AT1 receptors, the expression of which in CFs far exceeded that in cardiomyocytes (Lijnen et al., 2001). Stimulation with Ang II resulted in myocardial fibrosis in vivo (Kim et al., 1995) as well as CFs proliferation and collagen deposition in vitro (Ashizawa et al., 1996).

The root of Salvia miltiorrhiza BUNGE, known as Danshen in Chinese, is an herbal plant widely used to cure myocarditis and myocardial infarction (Chen et al., 1979). The traditional Chinese medicine Danshen, derived from the dried root or rhizome of
Salviae miltiorrhizae Bge, has been widely used for treatment of cardiovascular and cerebrovascular diseases. More than 30 diterpene compounds have been separated and identified from Danshen. Actually, Danshen-derived compounds have many important pharmacology effects in basic experiments or clinic, such as anti-tumor, immunoloregulation and cardioprotective effects, and so on (Kang et al., 2000; Su and Lin, 2008; Zhou et al., 2008). Tanshinone IIA is most abundant and structurally representative of the tanshinones of Salvia miItiorrhiza (Tang and Eisenbrand, 1992). Recently, STS was shown to be a promising drug that reduced cardiac remodeling through depressing cardiomyocyte hypertrophy (Yang et al., 2007). Moreover, STS was shown to possess antioxidant action (Zhou et al., 1999, 2003). Evidence shows that STS is an effective antioxidant that inhibits the 

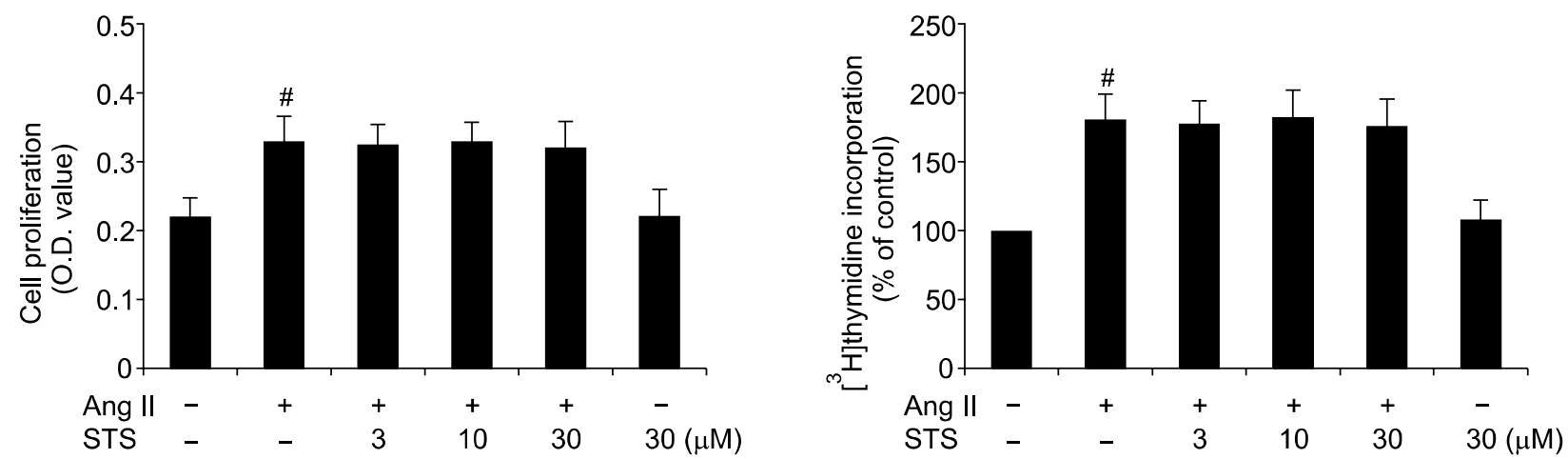

Figure 5. Effects of STS on Ang II-induced fibroblast proliferation. Cardiac fibroblasts were cultured in microplate and were incubated with STS (3, 10, 30 $\mu \mathrm{M})$. After $24 \mathrm{~h}$, cell proliferation was determined with the MTT assay and DNA synthesis assay ( $\left.{ }^{3} \mathrm{H}\right]$ thymidine incorporation). The experiments were reated five times with reproducible results. ${ }^{\sharp}<0.01$ vs. control.

formation of reactive oxygen radicals in rat heart mitochondria (Yang et al., 2008), breaks the chain reactions of peroxidation by scavenging lipid-free radicals and increases the activity of superoxide dismutase (Wang et al., 2008). Nevertheless, up to date, little is known about the cellular and molecular mechanisms of STS-mediated anti-fibrotic effects in cardiac fibroblasts after Ang II stimulation. In this study, we attempted to explore the effects and mechanisms of STS on Ang II-induced collagen type I expression in cultured CFs.

In this research, in vitro, we proved that Ang II $(0.1 \mu \mathrm{M})$ increased the expression and synthesis of collagen type I in CFs. In concordance with the increase of collagen expression, Ang II caused a significant increase in the rate of $\left[{ }^{3} \mathrm{H}\right]$ proline incorporation. These results were consistent with the previous reports (Lijnen et al., 2001; Chen et al., 2004c). The above effects were significantly depressed by the pretreatment with different concentrations of STS. Therefore, STS can depress the Ang II-induced collagen type I expression through attenuating collagen synthesis. Moreover, it is known that collagen type I accumulation in the heart depends not only on its production, but also on its degradation, which is performed by proteinases, such as matrix metalloproteinase-1 (MMP-1) (Brilla et al., 1994; D'Armiento et al., 2002; Heeneman et al., 2003). As it is shown in Figure 4, Ang II significantly depressed MMP-1 expression and activity, which accorded with the previous reports (Chen et al., 2004a, b; Lijnen et al., 2006; Pan et al., 2008). The pretreatment of STS can depress these effects of Ang II. However, the present study showed that STS did not induce obvious inhibitory effect on fibroblast proliferation, which is consistent
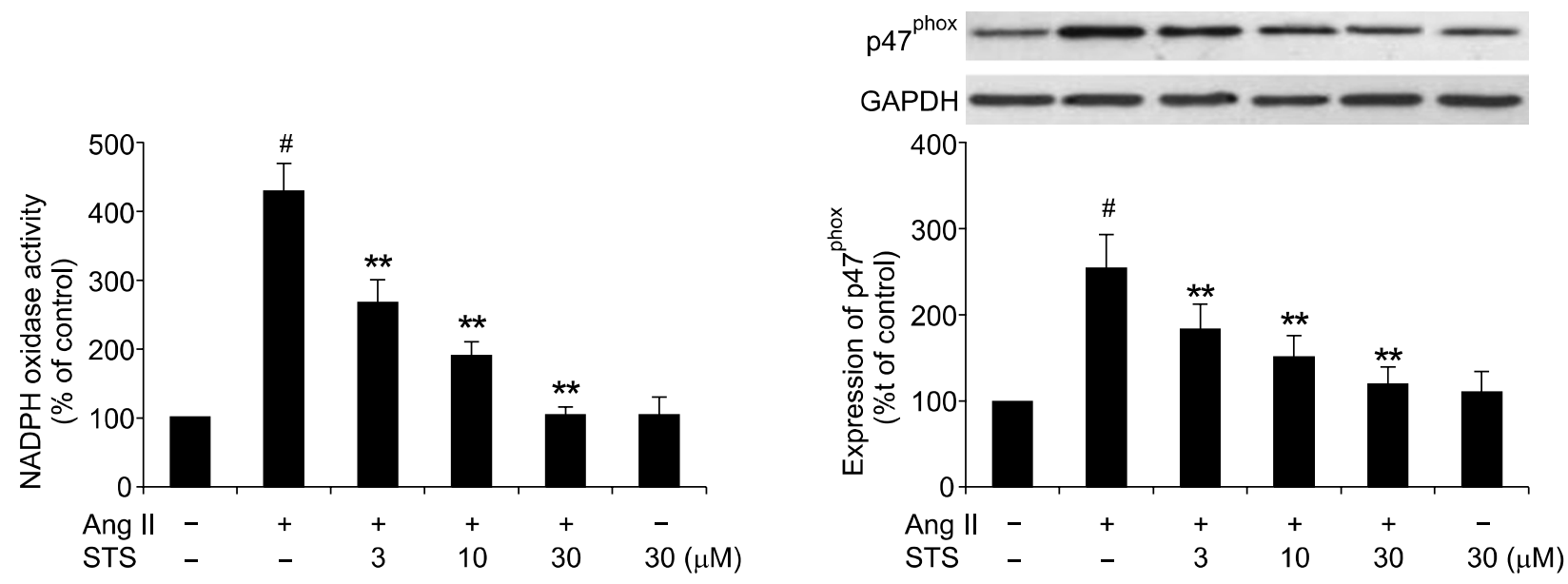

Figure 6. Effect of STS on Ang Il-induced NADPH oxidase activity and subunit $p 47^{\text {phox }}$ expression. Cardiac fibroblasts were pretreated with STS $(3,10,30$ $\mu \mathrm{M})$ for 30 min before stimulation with $0.1 \mu \mathrm{M}$ Ang II. After $24 \mathrm{~h}$, NADPH oxidase activity was measured by SOD-inhibitable cytochrome $c$ reduction and p $47^{\text {phox }}$ expression was measured by Western blot. The experiments were repeated five times with reproducible results. ${ }^{\sharp} P<0.01$ vs. control; ${ }^{* *} P<$ 0.01 vs. Ang II group. 
with the previous report (Takahashi et al., 2002). Interestingly, the effects of Ang II on CFs are different from the effects of Ang II in endothelial cells (Seeger et al., 2001) and cardiomyocytes (Rouet-Benzineb et al., 2000), wherein Ang II enhances MMP expression/activity. Therefore, Ang II affects MMP expression/activity differently in different cell types. The effects of STS on these areas are the fields we would explore in the future.

It is shown that Ang II enhances the ROS generation in CFs (Chen et al., 2006), which is confirmed in this study. In our research, STS depressed Ang II-stimulated ROS generation and depressed the effects of Ang II on collagen as well as MMP-1 expression in cardiac fibroblasts. Furthermore, the pretreatment of NAC, the ROS scavenger, exerted qualitatively similar effects as STS on collagen type I and MMP-1 expression in response to Ang II. From the above evidence, attenuation of ROS generation is, to a great extent, the basis of the observed effects of STS. NADPH oxidase is a major source of ROS and subunit $\mathrm{p} 47^{\text {phox }}$ plays a key role in Ang II-mediated NADPH oxidase activation (Lambeth et al., 2004; Murdoch et al., 2006). To determine the mechanisms of the anti-fibrotic effects of STS, we examined NADPH oxidase activity and subunit $\mathrm{p} 47^{\text {phox }}$ expression in CFs with the treatment of Ang II and STS. Ang II increased NADPH oxidase activity and subunit $\mathrm{p} 47^{\text {phox }}$ expression. These responses were markedly attenuated by treatment of STS.

Taken together, the present study delivers important new insights to the molecular mechanisms of actions of STS on cardiac fibroblasts. Our results indicated that STS markedly depresses Ang II-induced collagen type I expression in vitro. Moreover, STS could modulate the redox-sensitive steps involved in the Ang II signaling pathway. Although the precise mechanism by which STS depresses the development of cardiac fibrosis remains to be further clarified, understanding the pharmacologic actions of STS on cardiac fibroblasts may contribute to the choice of STS for the people who suffer from cardiovascular diseases.

\section{Methods}

\section{Materials}

One-day-old Wistar rats were obtained from Experimental Animal Center of Tongji Medical College, Grate II, and Certificate No 19-050. This research complied with the European Community Guidelines for the Care and Use of Experimental Animals and was approved by the Animal Research Committee of Tongji Medical College, Huazhong University of Science and Technology (Wuhan, China). STS $(99.5 \%)$ were obtained from the Research Center of
Traditional Chinese Medicine (Wuhan, China) and dissolved in PBS. Ang II and N-acetylcysteine (NAC) were obtained from Sigma-Aldrich (Saint Louis). Antibodies for collagen type I, MMP-1 and NADPH oxidase subunit p4 $7^{\text {phox }}$ were purchased from Santa Cruz Biotechnology Inc (Santa Cruz, CA). All other chemicals used were of the highest grade available commercially. The molecule structure of STS is shown in Figure 1.

\section{Cell cultures}

Rat cardiac fibroblasts were prepared and cultured as described earlier. Briefly, cardiac ventricles from one-dayold Wistar rats were separated and minced with scissors into small pieces in ice-cold balanced salt solution. Ventricular CFs were dispersed in $10 \mathrm{ml}$ Spinner solution of the following compositions (in $\mathrm{mM}$ ): $\mathrm{NaCl} 116$, HEPES 20, $\mathrm{NaH}_{2} \mathrm{PO}_{4}$ 12.5, glucose 5.6, $\mathrm{KCl} 5.4$, and $\mathrm{MgSO}_{4} 0.8$ $(\mathrm{pH} 7.35)$ containing $0.1 \%$ collagenase with agitation for 10 $\min$ at $37^{\circ} \mathrm{C}$. The digestion steps were repeated five to seven times until the tissues were completely digested. The cells were then combined, centrifuged, and re-suspended in a chilled fetal calf serum. After final collection, the cells were pelleted by centrifugation $(800 \times g$ for 10 min at room temperature). The supernatant was discarded, and the cells were re-suspended in DMEM. The resulting cell mixture was prep-plated for $1 \mathrm{~h}$ in a $5 \% \mathrm{CO}_{2}$-containing incubator at $37^{\circ} \mathrm{C}$ to plate out CFs. After removal of the myocyte-enriched medium, DMEM was then added to the pre-plated CFs which were cultured for 2 days before being passaged. Experiments were performed with cells from passage 3 .

\section{Western blot analysis}

The expressions of collagen type I, MMP-1 and subunit $\mathrm{p} 47^{\text {phox }}$ were determined by Western Blot. Fibroblasts from each group were pelleted and extracted in iced cell lysis buffer (Cell Signaling Technologies). Cell lysates were centrifuged at $15,000 \mathrm{~g}$ for $15 \mathrm{~min}$ at $4^{\circ} \mathrm{C}$ and the supernatants from each group were separated by $10 \%$ SDS-PAGE (for MMP-1) and $8 \%$ nondenatured-PAGE (for collagen type I) and then transferred to nitrocellulose membranes. After incubation in blocking solution $(5 \%$ nonfat milk, Sigma), membranes were incubated with primary antibodies (Sigma-Aldrich) overnight at $4^{\circ} \mathrm{C}$. Membranes were washed with $1 \times$ TBST solution and then incubated with secondary antibody (1:5,000 dilution, Amersham Life Sciences) for $2 \mathrm{~h}$. The membranes were detected with the ECL system (Amersham Life Sciences) and relative intensities of protein bands analyzed by Scan-gel-it software.

\section{Collagenase activity assay}

Active MMP-1 secreted into culture medium can be identified and quantified through gelatin zymography. Essentially, the conditioned culture medium was collected from the dishes and $10 \mu \mathrm{l}$ of the medium was subjected to electrophoresis in SDS polyacrylamide gel containing $0.1 \%$ gelatin under nonreducing conditions. The gels were soaked in $2.5 \%$ Triton-X100 for $60 \mathrm{~min}$ and then washed 
with water for $60 \mathrm{~min}$ to remove SDS. The gels were then incubated in a developing buffer containing $50 \mathrm{mM}$ Tris, $\mathrm{pH}$ $7.4,5 \mathrm{mM} \mathrm{CaCl}_{2}$, and $0.02 \%$ sodium azide for $18 \mathrm{~h}$ at $37^{\circ} \mathrm{C}$. After incubation, the gels were stained with Coomassie blue and photographed.

\section{MTT assay}

When achieving $50 \%$ confluence, CFs were starved for 24 $\mathrm{h}$ with DMEM and treated with STS $(3,10,30 \mu \mathrm{M})$ for 30 min before stimulation with $0.1 \mu \mathrm{M}$ Ang II. After $24 \mathrm{~h}$, cell proliferation was assessed by the MTT assay. The assay is based on the transformation of the tetrazolium salt MTT by active mitochondria to an insoluble formazan salt. MTT was added to each well under sterile conditions (with a final concentration of $5 \mathrm{mg} / \mathrm{ml}$ ), and the plates were incubated for $4 \mathrm{~h}$ at $37^{\circ} \mathrm{C}$. Untransformed MTT was removed by aspiration, and formazan crystals were dissolved in DMSO (150 $\mu \mathrm{l} /$ well). Formazan was quantified at $540 \mathrm{~nm}$ using a Bio-Rad automated EIA Analyzer.

\section{DNA and collagen synthesis assay}

DNA synthesis was evaluated by measuring $\left[{ }^{3} \mathrm{H}\right]$ thymidine incorporation and collagen synthesis was evaluated by measuring $\left[{ }^{3} \mathrm{H}\right]$ proline incorporation as described earlier (Zhang et al., 2007). In brief, cardiac fibroblasts were made quiescent by culture in serum-free DMEM for $24 \mathrm{~h}$. Then these cells were pretreated with STS $(3,10,30 \mu \mathrm{M})$ for 30 min before stimulation with $0.1 \mu \mathrm{M}$ Ang II for $24 \mathrm{~h}$. DNA synthesis was assessed by the addition of $1 \mu \mathrm{Ci} / \mathrm{ml}$ of $\left[{ }^{3} \mathrm{H}\right]$ thymidine (Amershan Biosciences) for a period of $4 \mathrm{~h}$ prior to the end of the treatment protocol. Collagen synthesis was assessed by the addition of $1 \mu \mathrm{Ci} / \mathrm{ml}$ $\left[{ }^{3} \mathrm{H}\right]$ proline (Amershan Biosciences) for a period of $6 \mathrm{~h}$. Cells were washed with PBS and ice-cold 10\% TCA. The cells were solubilized and the cell extracts analyzed in a liquid scintillation counter.

\section{Measurement of ROS production}

The determination of intracellular ROS production was based on the oxidation of 2',7'-dichlorodihydrofluorescein (DCFH) to a fluorescent 2',7'-dichlorofluorescein (DCF). Briefly, CFs were loaded with $20 \mu \mathrm{M}$ DCFH (Molecular Probes) for $30 \mathrm{~min}$ at $37^{\circ} \mathrm{C}$ in the dark. Cells loaded with DCFH were treated with STS $(3,10,30 \mu \mathrm{M})$ for $30 \mathrm{~min}$ before stimulation with $0.1 \mu \mathrm{M}$ Ang II. After $12 \mathrm{~h}$, the cells were washed twice with PBS and detached by trypsin, then measured for DCF fluorescence intensity by fluorospectrophotometer analysis at an excitation wavelength of $485 \mathrm{~nm}$ and at an emission wavelength of $530 \mathrm{~nm}$. The cell number in each sample was counted and utilized to normalize the fluorescence intensity of DCF.

\section{NADPH oxidase activity}

NADPH oxidase-dependent superoxide production was measured by SOD-inhibitable cytochrome c reduction as described previously (Lijnen et al., 2006). Cell homoge- nates were distributed in 96-well flat-bottom culture plates $(200 \mu \mathrm{l} / \mathrm{well})$. Cytochrome $\mathrm{c}(500 \mu \mathrm{M})$ and NADPH $(100$ $\mu \mathrm{M})$ were added in the presence or absence of SOD (200 $\mathrm{U} / \mathrm{ml}$ ) and incubated at room temperature for $30 \mathrm{~min}$. Cytochrome $\mathrm{c}$ reduction was measured by reading absorbance at $550 \mathrm{~nm}$ on a microplate reader. Superoxide production in nanomoles per milligram of protein was calculated from the difference between absorbance with and without SOD and extinction coefficient for change of ferricytochrome c to ferrocytochrome $\mathrm{c}$.

\section{Statistical analysis}

Results were expressed as mean \pm S.D. Statistical significance was determined using one-way ANOVA. The differences were considered statistically significant at a value of $P<0.05$.

\section{Acknowledgments}

This work was supported by grant 30500657 from the National Natural Science Foundation of China. The authors express their thanks to Dr. Li-Bo Zhao in Department of Pharmacology for his generous technical supports.

\section{References}

Ashizawa N, Graf K, Do YS, Nunohiro T, Giachelli CM, Meehan WP, Tuan TL, Hsueh WA. Osteopontin is produced by rat cardiac fibroblasts and mediates $\mathrm{A}(\mathrm{II})$-induced DNA synthesis and collagen gel contraction. J Clin Invest 1996; 98:2218-27

Brilla CG, Zhou G, Matsubara L, Weber KT. Collagen metabolism in cultured adult rat cardiac fibroblasts: response to angiotensin II and aldosterone. J Mol Cell Cardiol 1994; 26:809-20

Brown L. Cardiac extracellular matrix: a dynamic entity. Am J Physiol Heart Circ Physiol 2005;289:973-4

Brown RD, Jones GM, Laird RE, Hudson P, Long CS. Cytokines regulate matrix metalloproteinases and migration in cardiac fibroblasts. Biochem Biophys Res Commun 2007;362:200-5

Chen J, Mehta JL. Angiotensin II-mediated oxidative stress and procollagen-1 expression in cardiac fibroblasts: blockade by pravastatin and pioglitazone. Am J Physiol Heart Circ Physiol 2006;291:1738-45

Chen K, Chen J, Li D, Zhang X, Mehta JL. Angiotensin II regulation of collagen type I expression in cardiac fibroblasts: modulation by PPAR-gamma ligand pioglitazone. Hypertension 2004a;44:655-61

Chen K, Li D, Zhang X, Hermonat PL, Mehta JL. Anoxiareoxygenation stimulates collagen type-I and MMP-1 expression in cardiac fibroblasts: modulation by the PPAR-gamma ligand pioglitazone. J Cardiovasc Pharmacol 2004b;44: 682-7

Chen K, Mehta JL, Li D, Joseph L, Joseph J. Transforming growth factor beta receptor endoglin is expressed in cardiac 
fibroblasts and modulates profibrogenic actions of angiotensin II. Circ Res 2004c;95:1167-73

Chen W, Dong Y, Wang C, Ting G. Pharmacological studies of sodium tanshinone IIA sulfonate. Acta Pharmacol Sin 1979;14:277-83

Cohn JN, Ferrari R, Sharpe N. Cardiac remodeling-concepts and clinical implications: a consensus paper from an international forum on cardiac remodeling. Behalf on an international forum on cardiac remodelling. J Am Coll Cardiol 2000;35:569-82

D'Armiento J. Matrix metalloproteinase disruption of the extracellular matrix and cardiac dysfunction. Trends Cardiovasc Med 2002;12:97-101

Fedak PW, Verma S, Weisel RD, Li RK. Cardiac remodeling and failure: From molecules to man (Part II). Cardiovasc Pathol 2005;14:49-60

Gibbons $\mathrm{GH}$. The pathophysiology of hypertension: the importance of angiotensin II in cardiovascular remodeling. Am J Hypertens 1998;11:177-81

Heeneman S, Cleutjens JP, Faber BC, Creemers EE, van Suylen RJ, Lutgens E, Cleutjens KB, Daemen MJ. The dynamic extracellular matrix: intervention strategies during heart failure and atherosclerosis. J Pathol 2003;200:516-25

Jaana Rysä, Hanna Leskinen, Mika Ilves, Heikki Ruskoaho. Distinct upregulation of extracellular matrix genes in transition from hypertrophy to hypertensive heart failure. Hypertension 2005;45:927-33

Kang BY, Chung SW, Kim SH, Ryu SY, Kim TS. Inhibition of interleukin-12 and interferon-gamma production in immune cells by tanshinones from Salvia miltiorrhiza. Immunopharmacology. 2000;49:355-61

Kass DA, Bronzwaer JG, Paulus WJ. What mechanisms underlie diastolic dysfunction in heart failure? Circ Res 2004;94:1533-42

Kawano H, Do YS, Kawano Y, Starnes V, Barr M, Law RE. Angiotensin II has multiple profibrotic effects in human cardiac fibroblasts. Circulation 2000;101:1130-7

Kim S, Ohta K, Hamaguchi A, Yukimura T, Miura K, Iwao H. Angiotensin II induces cardiac phenotypic modulation and remodeling in vivo in rats. Hypertension. 1995;25:1252-9

Kumar R, Singh VP, Baker KM. The intracellular reninangiotensin system: implications in cardiovascular remodeling. Curr Opin Nephrol Hypertens 2008;17:168-73

Lambeth JD. NOX enzymes and the biology of reactive oxygen. Nat Rev Immunol 2004;4:181-9

Lijnen P, Papparella I, Petrov V, Semplicini A, Fagard R. Angiotensin II-stimulated collagen production in cardiac fibroblasts is mediated by reactive oxygen species. J Hypertens 2006;24:757-66

Lijnen PJ, Petrov VV, Fagard RH. Angiotensin II-induced stimulation of collagen secretion and production in cardiac fibroblasts is mediated via angiotensin II subtype 1 receptors. J Renin Angiotensin Aldosterone Syst 2001;2:117-22

Murdoch CE, Grieve DJ, Cave AC, Looi YH, Shah AM NADPH oxidase and heart failure. Curr Opin Pharmacol
2006;6:148-53

Pan $\mathrm{CH}$, Wen $\mathrm{CH}$, Lin CS. Interplay of angiotensin II and angiotensin(1-7) in the regulation of matrix metalloproteinases of human cardiocytes. Exp Physiol 2008;93: 599-612

Rouet-Benzineb P, Gontero B, Dreyfus P, Lafuma C. Angiotensin II induces nuclear factor-kappa B activation in cultured neonatal rat cardiomyocytes through protein kinase C signaling pathway. J Mol Cell Cardiol 2000;32:1767-78

Seeger H, Lippert C, Wallwiener D, Mueck AO. Valsartan and candesartan can inhibit deteriorating effects of angiotensin II on coronary endothelial function. J Renin Angiotensin Aldosterone Syst 2001;2:141-3

Su CC, Lin YH. Tanshinone IIA down-regulates the protein expression of ErbB-2 and up-regulates TNF-alpha in colon cancer cells in vitro and in vivo. Int J Mol Med. 2008;22: 847-51

Sun Y, Weber KT. RAS and connective tissue in the heart. Int J Biochem Cell Biol 2003;35:919-31

Takahashi K, Ouyang X, Komatsu K, Nakamura N, Hattori M, Baba A, Azuma J. Sodium tanshinone IIA sulfonate derived from Danshen (Salvia miltiorrhiza) attenuates hypertrophy induced by angiotensin II in cultured neonatal rat cardiac cells. Biochem Pharmacol 2002;64:745-9

Tang W, Eisenbrand G. Salvia miltiorrhiza Bge. Chinese drugs of plant origin, 1992, 891-902, Springer, Berlin, Germany.

Wang XW, Wu L, Miao MS, Zhu D, Xing YL, Ma YJ, Zhong ZY, Zhou Z, Wang SQ. WITHDRAWN: Tanshinone IIA protects rat cardiomyocytes against apoptosis induced by angiotensin II in vitro. Eur J Pharmacol 2008 Jul 17. (Epub ahead of print)

Weber KT, Brilla CG. Pathological hypertrophy and cardiac interstitium. Fibrosis and renin-angiotensin-aldosterone system. Circulation 1991;83:1849-65

Weber KT, Sun Y, Tyagi SC, Cleutjens JP. Collagen network of the myocardium: function, structural remodeling and regulatory mechanisms. J Mol Cell Cardiol 1994;26:279-92

Weber KT, Sun Y, Katwa LC, Cleutjens JP. Connective tissue: a metabolic entity? J Mol Cell Cardiol 1995;27:107-20

Wood DA. Preventing clinical heart failure: the rationale and scientific evidence. Heart 2002;88:15-22

Yang L, Zou X, Liang Q, Chen H, Feng J, Yan L, Wang Z, Zhou D, Li S, Yao S, Zheng Z. Sodium tanshinone IIA sulfonate depresses angiotensin II-induced cardiomyocyte hypertrophy through MEK/ERK pathway. Exp Mol Med 2007;39:65-73

Yang R, Liu A, Ma X, Li L, Su D, Liu J. Sodium tanshinone IIA sulfonate protects cardiomyocytes against oxidative stress-mediated apoptosis through inhibiting JNK activation. J Cardiovasc Pharmacol 2008;51:396-401

Zhang H, Pi R, Li R, Wang P, Tang F, Zhou S, Gao J, Jiang J, Chen S, Liu P. PPARbeta/delta activation inhibits angiotensin II-induced collagen type I expression in rat cardiac fibroblasts. Arch Biochem Biophys 2007;460:25-32

Zhao BL, Jiang W, Zhao Y, Hou JW, Xin WJ. Scavenging 
effects of salvia miltiorrhiza on free radicals and its protection for myocardial mitochondrial membranes from ischemiareperfusion injury. Biochem Mol Biol Int 1996;38:1171-82

Zhou G, Jiang W, Zhao Y, Ma G, Xin W, Yin J, Zhao B. Sodium tanshinone IIA sulfonate mediates electron transfer reaction in rat heart mitochondria. Biochem Pharmacol 2003;65:51-7

Zhou GY, Zhao BL, Hou JW, Ma GE, Xin WJ. Protective effects of sodium tanshinone IIA sulphonate against adriamycin-induced lipid peroxidation in mice hearts in vivo and in vitro. Pharmacol Res 1999;40:487-91

Zhou L, Shao Y, Huang Y, Yao T, Lu LM. 17beta-estradiol inhibits angiotensin II-induced collagen synthesis of cultured rat cardiac fibroblasts via modulating angiotensin II receptors. Eur J Pharmacol 2007;567:186-92

Zhou L, Chan WK, Xu N, Xiao K, Luo H, Luo KQ, Chang DC. Tanshinone IIA, an isolated compound from Salvia miltiorrhiza Bunge, induces apoptosis in HeLa cells through mitotic arrest. Life Sci. 2008;83:394-403 